\title{
O “Menor Infrator” na Mídia: Etnografia da Criminalização da Pobreza no G1
}

\author{
Francyne dos Santos Andrade ${ }^{1}$ \\ ${ }^{1}$ Universidade Católica de Petrópolis, RJ, Brasil.
}

\author{
Cristiane Moreira da Silva ${ }^{1}$ \\ ${ }^{1}$ Universidade Católica de Petrópolis, RJ, Brasil.
}

Rosilene Ribeiro ${ }^{1}$

${ }^{1}$ Universidade Católica de Petrópolis, RJ, Brasil.

\begin{abstract}
Resumo: A mídia ocupa espaço expressivo na contemporaneidade, produzindo significações sobre fenômenos cotidianos, divulgando-os massivamente e, assim, definindo não só o que existe e o que faz parte da realidade, mas promovendo conotações valorativas sobre os acontecimentos. No contexto brasileiro, a mídia tem sido o principal vetor no que se refere às subjetivações sobre fenômenos da violência e da criminalidade. Tendo como objeto de pesquisa a repercussão no portal de notícias G1 de dois casos cujos protagonistas são jovens envolvidos em atos infracionais, este estudo mapeou as reportagens vinculadas a estes de modo a compreender as subjetividades produzidas, promovendo uma reflexão crítica a respeito da produção do "menor infrator" na mídia e seus desdobramentos. O método empregado para a realização do estudo foi a etnografia on-line, em consonância com os princípios da Teoria AtorRede. O rastreamento das matérias promoveu reflexões sobre a produção do "menor infrator", entre elas a percepção de que, tal como as políticas de subjetivação vetorizadas por esses dispositivos, as práticas que criminalizam a juventude pobre ocorrem de modo bastante sutil. É na constante ênfase dada pela mídia a elementos morais específicos e na arbitrariedade com a qual se destaca ou não a presença de transtornos psicológicos que vemos um caso ser tratado como punição merecida e o outro como tragédia. Assim, a veiculação de notícias que envolvem jovens tem se configurado uma importante tática de segregação e exclusão social, promovendo o apoio social às práticas de segurança pública que punem e exterminam jovens pobres.
\end{abstract}

Palavras-chave: Mídia, Produção de Subjetividade, Infração Juvenil, Etnografia On-line, G1.

\section{The "Juvenile Offender" on the Media: Ethnography of Poverty Criminalization in G1}

\begin{abstract}
The media produce meanings about everyday phenomena, spreading them massively and creating value connotations about events. In Brazil, this has been the main vector when it comes to the subjectivities about the phenomena of violence and criminality. Taking as research object the repercussion of the G1 news portal about two cases where the protagonists are young boys involved in infractions, this study mapped the reports related to them in order to understand the produced subjectivities, promoting a critical reflection on the production of the "juvenile offender" in the media and its consequences. The method used to carry out the study was an on-line ethnography, in accordance with the principles of the Actor-Network Theory. The tracking of the subjects allowed to reflect on the production of the "juvenile offender", being one of them the perception that, just like the policies of subjectivation vectored by these devices, the practices that criminalize the poor and young population happen in a very subtle way. The constant emphasis given by the media to specific moral elements and the arbitrariness with which the presence of psychological disorders is highlighted or not shows one case being treated
\end{abstract}


as a deserved punishment and the other as a tragedy. This is how the news coverage involving young people serves as an important tactic of segregation and social exclusion, promoting social support for public safety and security practices that punish and exterminate poor young people. Keywords: Media, Subjectivity Production, Juvenile Delinquency, Ethnography Online, G1.

\title{
El “Menor Infractor" en Los Medios: Etnografía de la Criminalización de la Pobreza en el Portal G1
}

\begin{abstract}
Resumen: Los medios ocupan un espacio significativo en la contemporaneidad al producir significaciones acerca de los fenómenos cotidianos, divulgarlos masivamente y definir no solo lo que existe y lo que es parte de la realidad, sino también promocionar connotaciones valorativas sobre los acontecimientos. En el contexto brasileño, los medios han sido el principal vector en lo que se refiere a las subjetivaciones sobre los fenómenos de la violencia y de la criminalidad. Teniendo como el objeto de la investigación la repercusión en el portal de noticias G1 de dos casos que tienen como protagonistas jóvenes que se involucraron en actos delictivos, la investigación ha mapeado los reportajes vinculados para comprender las subjetividades producidas al hacer una reflexión crítica a respeto de la producción acerca del "menor infractor" en los medios y sus implicaciones. Se utilizó la etnografía en línea según los principios de la teoría actor-red como método de investigación. El rastreo de los reportajes permitió reflexionar sobre la producción acerca del "menor infractor", entre ellas la percepción de que, tal como las políticas de subjetivación vectorizadas por estas plataformas, las prácticas que criminalizan la juventud pobre ocurren de modo bastante sutil. Sin embargo, es en el constante énfasis dado por los medios a elementos morales específicos y en la arbitrariedad con la cual se destaca o no la presencia de trastornos psicológicos que vemos un caso ser tratado con la debida punición y el otro, como una tragedia. La difusión de noticias que involucran a los jóvenes se traduce en una importante táctica de segregación y exclusión social, fomentando el apoyo social a prácticas de seguridad pública que castigan y exterminan a los jóvenes pobres.
\end{abstract}

Palabras clave: Medios, Producción de Subjetividad, Delito Juvenil, Etnografía en Línea, Portal G1.

\section{Introdução}

Cena 1 - "Sou ladrão e vacilão"1: um jovem de 17 anos foi acusado de roubo e mantido em cárcere privado por dois homens que o torturaram e tatuaram os dizeres "sou ladrão e vacilão" em sua testa como forma de punição. A cena foi filmada pelos agressores e exposta nas redes sociais. O caso, ocorrido em junho de 2017 no ABC Paulista, ganhou grande repercussão na mídia, promovendo intensos debates em relação às práticas de justiçamento ${ }^{2}$, redução da maioridade penal, uso de drogas e direitos humanos. Os tatuadores foram presos e o adolescente internado em uma clínica para tratamento da dependência química. No início de 2018, o caso ganha novamente visibilidade, após o adolescente sair da clínica e ser preso por furtar desodorantes.

Cena 2 - "Atirador na escola"3: um adolescente de catorze anos, filho de policiais militares, efetuou 40 disparos contra colegas de classe dentro de uma escola particular, em Goiânia, em outubro de 2017, matando

\footnotetext{
${ }^{1}$ Recuperado de https://g1.globo.com/sao-paulo/noticia/tatuador-e-preso-por-tortura-apos-escrever-eu-sou-ladrao-e-vacilao-natesta-de-adolescente-no-abc.ghtml

${ }^{2}$ Ato ou efeito de justiçar; de punir com morte ou castigo físico severo, por meio de julgamentos ilegais conduzidos por governos de exceção ou grupos justiceiros.

${ }^{3}$ Recuperado de https://g1.globo.com/goias/noticia/escola-tem-tiroteio-em-goiania.ghtml.
} 
dois alunos e ferindo quatro. A arma utilizada, uma pistola .40 , pertencia à mãe do adolescente, que foi impedido de continuar o ataque pela coordenadora da escola. O crime teria sido planejado por ele como forma de vingança por sofrer bullying. O caso ganhou notório destaque na mídia e nas redes sociais, chocando a população e reacendendo os debates sobre as consequências da violência física e psicológica exercida principalmente em forma de agressões, zombarias, apelidos e xingamentos - no contexto escolar.

Tomando como analisadores as cenas descritas, o seguinte problema norteou esta pesquisa: que discursos são produzidos e quais seus efeitos na discussão sobre criminalidade e juventude? O objetivo principal foi discutir como conteúdos midiáticos produzem a figura do "menor infrator" atrelado à classe social. Para a investigação, utilizamos o método da etnografia na cibercultura (Segata \& Rifiotis, 2016) apoiado na Teoria Ator-Rede (Latour, 2012). Foram acompanhadas as reportagens no site de notícias G1 - O Portal de Notícias da Globo, vinculadas às duas cenas, buscando identificar que realidades as narrativas atribuídas a cada caso construíram.

Segundo a nota técnica "O Adolescente em conflito com a Lei e o debate sobre a Redução da Maioridade Penal: esclarecimentos necessários", elaborada pelo Instituto de Pesquisa Econômica Aplicada-Ipea (2013), o reaparecimento de tempos em tempos de discussões acerca da redução da maioridade penal "é pautado em matérias veiculadas na grande mídia e ganham tons alarmistas, aumentando o medo e a sensação de insegurança" (p. 2). Como resultado, surgem propostas diversas visando a modificação da legislação a respeito da maioridade penal, seja para diminuir de forma direta - abaixando a idade - seja de forma indireta aumentando o tempo de internação dos adolescentes autores de ato infracional.

Uma vez que a população se mostra cada vez mais indignada com a impunidade, com a violência e parece perder a confiança nas instituições de justiça, projetos como este ganham força, pois, à primeira vista, parecem trazer soluções viáveis para lidar com o problema da violência e aplacar o medo coletivo. Tratando-se de uma medida com forte impacto na vida de milhares de adolescentes e suas famílias, é urgente pensar seus efeitos e promover discussões mais abrangentes.

Para além dessas discussões, pensar a produção do "menor infrator" pela mídia envolve outros desdobramentos pertinentes ao campo de estudo da Psicologia Social. Interessa-nos, aqui, a capacidade que os dispositivos midiáticos têm de operar em nós formas de compreender o mundo, modelando nossas subjetividades e direcionando o modo como interpretamos acontecimentos. Entretanto, ao propormos uma reflexão mais crítica sobre o assunto, percebemos que a mídia frequentemente é agente violador de direitos e, ao mesmo tempo, é produtora de violações por parte de seu público, por meio do livre espaço de manifestação concedido a este para comentários discriminatórios e manifestações de ódio gratuitas.

Os resultados evidenciaram que o tratamento dos casos atribui perigo a determinada classe social e a necessidade de cuidados em saúde mental a outra. No caso "Sou ladrão e vacilão", temos, de um lado, a produção de um adolescente marcado pela ideia de periculosidade, de marginalidade e, de outro, a produção de subjetividades sujeitas à punição e ao encarceramento, que reforçam a ideia de que a punição violenta seria solução para criminalidade. Em contraponto, o "Atirador na escola" é uma vítima de bullying que se envolveu em uma tragédia devido aos danos em sua saúde mental e, consequentemente, precisa de cuidados. Não questionamos a importância de um olhar para todas as forças envolvidas no caso, mas apontamos as diferenças nos argumentos e conceitos utilizados para discussão no Gl. O adolescente do caso "ladrão e vacilão", mesmo sendo dependente químico, em momento algum teve sua saúde mental como atenuante para a interpretação do possível "crime" que iria cometer.

Limitar a leitura dos fatos a causas individuais e atravessadas por preconceitos de classe impede discussões de caráter mais amplo, tais como desigualdades sociais, direitos humanos e políticas públicas, temas entremeados pela questão e que podem servir de base para a criação de estratégias mais efetivas de enfrentamento ao problema.

\section{Mídia, subjetividade e infração juvenil: da construção do termo "menor" ao lugar do infrator}

Historicamente construído, o termo "menor" resulta na produção desse indivíduo como sujeito anormal, perigoso e possuidor de uma índole ruim (Cairo \& Milanez, 2011, p. 3), carregando em si todo um significado de exclusão, oriundo de um processo segregacionista que parece produzir uma clara distinção 
entre crianças e menores: "Às crianças são dadas todas as possibilidades para seu desenvolvimento, porque, afinal de contas, são crianças. Aos menores é reservado o lugar do perigoso, do ameaçador, daquele que irá desconstruir as estruturas da sociedade e seu bom funcionamento (Silva, 2017, p. 13).

Enquanto o menor - relativo à infância pobre é considerado perigoso, a criança - referente à infância abastada - parece ser protegida e resguardada das ameaças das ruas. Segundo Fernando Torres Londoño (1991), foi por meio de jornais, revistas jurídicas e conferências acadêmicas que se definiu a imagem do "menor" como criança pobre, totalmente desprotegida, moral e materialmente, por pais, tutores, pelo Estado e pela sociedade.

No fim do século XIX, ... os juristas brasileiros descobrem o "menor" nas crianças pobres das cidades, que por não estarem sob a autoridade de seus pais e tutores são chamadas por eles de abandonadas. Eram, pois, menores abandonados as crianças que povoavam as ruas do centro das cidades, os mercados, as praças e, por incorrer no delito, frequentavam também o xadrez e cadeia, neste caso passando a ser chamadas de menores criminosos (Londoño, 1991, p. 135).

Pelo trecho citado, percebe-se a ideia de periculosidade sendo associada ao "menor" e, em caráter mais amplo, à pobreza. Historicamente, tal associação se dá principalmente por meio das práticas higienistas presentes no Brasil no século XX, influenciadas pelos movimentos eugênicos do século XIX na Europa. Promovidas por uma elite cientifica composta majoritariamente por médicos, psiquiatras, pedagogos e juristas, tais práticas se baseiam nas teorias racistas e no darwinismo social, pregando o aperfeiçoamento da raça e colocando-se abertamente contra negros e mestiços - a maior parte da população pobre brasileira.

O higienismo, aliado aos ideais eugênicos e à teoria da degenerescência de Morel, concebe que os vícios e as virtudes são, em grande parte, originários dos ascendentes. Afirma que aqueles advindos de "boas famílias" teriam naturalmente pendores para a virtude. Ao contrário, aqueles que traziam "má herança", leia-se os pobres, seriam portadores de degenerescências. Dessa forma, justifica-se uma série de medidas contra a pobreza, que passa a ser percebida e tratada como possuidora de uma "moral duvidosa" transmitida hereditariamente (Coimbra \& Nascimento, 2005, p. 17).

É obedecendo a lógicas higienista que se dá a emergência do Juizado de Menores, em 1923, criado para solucionar o problema da "infância e juventude desassistidas" e, em 1927, surge a primeira lei no país específica para a infância e adolescência, o Código de Menores. Resultante da aliança entre médicos e juristas da época, "o Código estabelecido pelo Decreto $n^{\circ} 17.943-A$, de 12 de outubro de 1927, passa para a alçada do Estado a função de atender o "menor" de dezoito anos, visando aquele tido como delinquente e abandonado" (Silva, 2017, p. 16).

A partir desse momento, institui-se a vigilância das autoridades públicas sobre as famílias menos abastadas, fortalecendo a percepção da pobreza e do abandono como elementos patogênicos. Coimbra e Nascimento (2005) corroboram com essa perspectiva, situando a ideia de periculosidade associada aos pobres e aos seus filhos, fazendo-se necessário que estes sejam combatidos, excluídos-e encarcerados, uma vez que poderiam compor as chamadas "classes perigosas".

Fica evidente que a elaboração do Código de Menores não foi pautada em atender os menores de idade de todas as classes sociais, mas sim em construir o que Silva (2017) chama de "aparato jurídico-social para a criminalização das crianças e adolescentes pobres" (p. 19), produzindo infâncias e juventudes desiguais e aumentando ainda mais o abismo entre os "menores" e as "crianças" - estas referem-se apenas àquelas inseridas nas famílias de classe média, consideradas estruturadas e modelos da virtude.

Essa produção da desigualdade tem se expressado ao longo de todo o século XX e se fortaleceu por meio da massiva prática de internação das crianças e jovens pobres, em especial após a criação de órgãos como o Serviço de Assistência ao Menor (SAM), implantado em 1941 durante o Estado Novo, e a Fundação Nacional do Bem-Estar do Menor (Funabem), que surge em 1964 durante o período da ditadura militar no Brasil.

Somente no final da década de 1980 irrompe uma nova perspectiva em relação à infância e à adolescência, após a aprovação do texto constitucional de 1988, que originou a substituição do Código de Menores pelo Estatuto da Criança e do Adolescente (ECA) em 1990. A partir desse momento, supera-se a Doutrina da Situação Irregular, abandonando a concepção de 
"menor" como objeto de intervenção do Estado, estabelecendo-se a Doutrina da Proteção Integral como referência para a formulação e implantação de políticas públicas, reconhecendo todas as crianças e adolescentes, sem exceção alguma, como sujeitos de direitos.

Apesar dos avanços estabelecidos pela nova legislação, a marca construída pela associação entre pobreza e delinquência se faz presente nas subjetividades dos brasileiros até hoje, não conseguindo romper, como bem nos alerta Coimbra e Nascimento (2005), com a lógica de exclusão existente em mais de 400 anos de história jurídico-político-social no Brasil.

Pensar nestas marcas e no que elas têm produzido em nós enquanto sociedade é pensar em nossos processos de subjetivação. Guattari e Rolnik (1986) compreendem a subjetividade como determinado modo de vida, a maneira como habitamos, sentimos, percebemos e compreendemos o mundo. Tal modo de compreensão tem, necessariamente, um caráter social, histórico e político. Nesse sentido, os autores apontam para uma subjetividade que é produzida, construída no tempo e na história, rompendo com a tradição das ciências humanas - em que o sujeito seria produto de uma suposta natureza humana - e apontam para uma produção de subjetividade "essencialmente fabricada, modelada, recebida, consumida" (Guattari \& Rolnik 1986, p. 31).

A subjetivação, ou produção de subjetividade, é um processo permanente e interminável, ocorrendo não apenas no campo individual, mas no campo social e material, fazendo que seja impossível separar um sujeito ou um fenômeno dos componentes sociais que o atravessam. O modo de ser indivíduo é apenas um dos modos de subjetivação possíveis, cabendo a cada época e sociedade colocar em funcionamento alguns desses modos em vez de outros.

Atentando para o fato de que essa produção subjetiva é operada por diversos dispositivos presentes na contemporaneidade, somos convidados constantemente a problematizar como a crescente presença das tecnologias de informação e de comunicação em todas as esferas da vida social contemporânea rearticulam experiências sociais, possibilitam novas formas de interação e trazem à tona outras formas de produção de si. Desse modo, destaca-se a capacidade que os dispositivos midiáticos têm de operar em nós uma modelagem de nossas subjetividades, uma produção de nossas formas de compreender o mundo, especialmente em relação ao entendimento dos fenômenos sociais. De acordo com Coimbra (2001),

As formas como a mídia produz real, verdades, fantasias, falas autorizadas, história e memória também atravessam os temas sobre a violência quando estão sendo marcados e identificados, por esses meios de comunicação, os "suspeitos", os "enfermos", os "discrimináveis", os "perigosos", os "infames". Aqueles que são considerados suspeitos, quando não estão tomando conta dos nossos filhos, limpando nossas casas, entrando pelo elevador de serviço (p. 58).

De acordo com Coimbra (2004), a mídia, no contexto brasileiro, tem sido o principal vetor no que se refere às subjetivações acerca dos fenômenos da violência e criminalidade, e na prática vem dificultando "qualquer processo de transformação social, ao reforçar a periculosidade daqueles que estão presos, ou cometem crimes/atos infracionais, produzindo medo e o desejo de eliminação dessa parcela da população" (p. 3).

Nessa lógica de medo e repressão, novas leis parecem se tornar necessárias, e não é por acaso que encontramos inúmeras propostas de alteração do ECA tramitando no Congresso Nacional, justificadas na menção aos clamores sociais por punições mais severas, que reaparecem nos momentos de repercussão de crimes que tenham como principal autor, um jovem (Teixeira, 2015).

A defesa da redução da maioridade penal é baseada na crença de que a repressão e a punição são os melhores caminhos para lidar com os conflitos e faz parte de um fenômeno de "tolerância zero" ao crime, composto por sentimentos fortes de punição, vingança e apelo à maior repressão policial. De acordo com Bocco (2006), as matrizes da mentalidade que têm guiado essas discussões contam com a mídia como grande incentivadora do pânico irracional com relação aos jovens pobres.

Dados recentes (Brasil, 2017; Flacso Brasil, 2015; Instituto de Pesquisa Econômica Aplicada, 2013) apontam que, nos últimos anos, delitos considerados graves, como homicídios, latrocínio, lesão corporal e estupro, alcançaram, juntos, apenas $11,7 \%$ do total dos atos praticados pelos adolescentes detidos no Brasil. Vale ressaltar ainda que, de acordo com os dados levantados, atualmente cerca de $60 \%$ dos adolescentes privados de liberdade são negros, $51 \%$ não 
frequentam a escola e $66 \%$ vivem em famílias consideradas extremamente pobres.

Entretanto, as condições de vulnerabilidade dificilmente são expostas pela mídia, que considera apenas os delitos praticados, noticiando-os frequentemente de modo sensacionalista e pouco comprometido com os inúmeros fatores que levam às práticas de infração. Como resultado, a audiência é direcionada a reagir com repúdio à juventude pobre, demonizando-a e configurando esta enquanto "peça essencial na campanha de atemorização pública, pois cria o fenômeno que pretende relatar por meio do convencimento da classe média de que precisa proteger-se e manter as classes perigosas afastadas" (Bocco, 2006, p. 95).

De acordo com Oliveira (2001), apesar de não haver evidências a respeito do aumento da violência na infração juvenil, nem de que as medidas socioeducativas sejam efetivas para reduzir os supostos crimes, muito menos de que a redução da idade penal sirva como estratégia de enfrentamento dos problemas sociais, a culpabilização da criminalidade parece recair sobre a juventude pobre, fortalecendo práticas de discriminação.

Por essa razão, falar da infração juvenil não é falar de um fato isolado. É dizer a respeito do modo de subjetivação contemporâneo e propor uma análise de como funcionamos enquanto sociedade, como produzimos infâncias e juventudes desiguais, como criminalizamos os pobres, como organizamos o mundo do trabalho, do ensino, da cultura e como judicializamos ${ }^{4}$ a vida.

\section{Etnografia on-line no G1: a entrada em campo}

Esta pesquisa se caracteriza como um estudo etnográfico na cibercultura. Configurando-se numa modalidade de pesquisa interpretativa, a etnografia propõe uma análise descritiva dos significados simbólicos, conotativos e denotativos que informam as práticas usuais na vida cotidiana (Uzzell \& Barnett, 2010).

De acordo com Segata e Rifiotis (2016), a etnografia situa a cibercultura para o lugar onde essa é produzida cotidianamente: nas práticas, experiências e sensibilidades da vida vivida, e não daquela imaginada. Trata-se, portanto, de um lugar onde pessoas, artefatos e outros seres são atravessados e produzidos com e pelas tecnologias digitais.

A partir da reflexão provocada pelas inquietações do campo, os autores supracitados propõem uma articulação com a Teoria Ator-Rede (TAR), passando a tratar a etnografia em termos de rastreamento e descrição de associações entre humanos e não humanos no curso de suas ações. Assim, a TAR passa a ser uma importante estratégia de entrada no campo da cibercultura, possibilitando romper com certas dualidades e justaposições (on-line versus off-line, técnico versus social, sujeito versus objeto), que dificultam o trabalho etnográfico. Tal combinação teórico-metodológica aponta uma entrada no campo da cibercultura que procure descrever como algo/alguém faz algo/alguém fazer, produzindo uma visibilidade singular de fluxos, mostrando a pluralidade e hibridação dos agentes em ação (Rifiotis, 2016).

Desse modo, propõe-se uma pesquisa que segue a TAR e seu enfoque construtivista, não dialético e pragmático, que "redimensiona a abordagem sobre as relações entre indivíduo e sociedade, entre natureza e cultura, apresentando uma epistemologia política normativa extremamente interessante para a psicologia social" (Arendt \& Tsallis, 2006, p. 67).

O campo escolhido para a realização da etnografia foi o site do G1 - Portal de Notícias da Globo. Tal escolha se dá considerando o levantamento Digital News Report, feito pela Reuters Institute ${ }^{5}$, vinculada à University of Oxford, em 2016. De acordo com o levantamento, no último semestre de 2016, o site G1 é apontado como o portal de notícias mais acessado pelos brasileiros, com 246 milhões de acessos. Ainda segundo os dados da pesquisa, entre os doze países estudados no continente americano, o Brasil é o que mais consome notícias on-line, prática atribuída a $72 \%$ dos usuários da internet, que representam $54 \%$ da população (o equivalente a 108 milhões de pessoas). Esses dados ajudam a salientar a relevância de estudos nesse veículo.

O período do trabalho etnográfico proposto compreende oito meses. Foram incluídas matérias vinculadas ao caso "sou ladrão e vacilão" (cena 1), no período de junho a setembro de 2017, e no caso do

\footnotetext{
${ }^{4}$ Por judicialização, compreende-se o movimento de regulação normativa e legal do viver, do qual os sujeitos se apropriam para a resolução dos conflitos, reproduzindo uns com os outros o controle, o julgamento e a punição das condutas.

${ }^{5}$ Reuters Institute for the Study of Journalism (RISJ) é um instituto de pesquisa em jornalismo e mídia global vinculado a Universidade de Oxford, no Reino Unido.
} 
"atirador na escola em Goiânia" (cena 2), de outubro de 2017 a janeiro de 2018.

Seguindo a proposta metodológica da etnografia, os dados coletados a partir das buscas no site foram registrados e descritos por meio de autorregistro, utilizando a técnica de diário de campo, contendo em sua formulação os seguintes aspectos: data da busca realizada, data em que a notícia foi publicada, a manchete utilizada, o conteúdo exposto, os links estabelecidos com outras reportagens, além das imagens e vídeos utilizados. Ao final, um relatório do diário de campo foi desenvolvido, apresentando a descrição dos dados.

A discussão dos achados foi realizada de modo a tomar o portal de notícias como um actante, um disparador não humano feito por humanos, que traduz e cria a realidade por meio de algoritmos que selecionam o que mostrar a quem, fazendo existir (enact) certa forma de compreensão desta. Utilizando-se da TAR como estratégia de entrada no campo, os dados etnográficos serão discutidos procurando evidenciar as práticas que conectam as tecnologias de comunicação, os usuários e os efeitos dessas associações.

\section{As práticas de criminalização da pobreza no $\mathbf{G} 1$}

A respeito do site analisado, há certa consistência no padrão das notícias: em destaque, logo no começo de cada matéria encontram-se as manchetes seguidas de uma pequena chamada que informa aspectos encontrados ao longo do texto. Alinhado ao canto esquerdo, aparecem o nome do jornalista, a especificação da redação à qual este está ligado, data e hora da publicação, seguida de data e hora da atualização que o texto sofreu. Observa-se ainda que, antes do corpo do texto, há sempre presença de uma imagem ou vídeo vinculados aos casos em questão.

Os parágrafos iniciais são sempre referentes ao texto da chamada e, em seguida, o texto se divide em seções com títulos específicos que, em geral, fazem uma espécie de reconstrução do que já foi informado anteriormente. Para além do texto, vídeos e fotos foram atrelados a cada uma das reportagens, além de links que redirecionam para notícias publicadas anteriormente.

Na cena 1, um jovem de dezessete anos, morador de São Bernardo do Campo, ABC Paulista, teve suas mãos e pés amarrados em uma cadeira e sua testa tatuada com os dizeres "sou ladrão e vacilão". O jovem, que apresenta transtornos psicológicos e usa drogas, encontrava-se desaparecido antes do incidente. Seu paradeiro somente foi localizado alguns dias depois do vídeo da agressão ter sido disseminado rapidamente pelas redes sociais, chegando a seus familiares, que o reconheceram e levaram as imagens até a polícia. A partir disso, os agressores foram presos e indiciados pelo crime de tortura, e a imagem do adolescente com a tatuagem na testa gerou intensa repercussão nas mais diferentes mídias, dentre elas o G1.

Ao longo dos meses de junho, julho, agosto e setembro de 2017, foram localizadas dezenove matérias vinculadas ao caso. Um único autor foi responsável por todos os textos publicados, tendo a participação de outros três jornalistas em apenas seis reportagens.

Acompanhando cronologicamente cada uma das notícias, percebe-se que o vídeo pelo qual o caso ficou conhecido apareceu em seis das reportagens analisadas. No vídeo, há uma pequena edição para que o rosto do adolescente não fosse identificado. Além disso, a foto em que o jovem aparece com a testa tatuada está presente em dezessete das dezenove matérias.

Nas primeiras reportagens, observa-se apenas a explanação do caso, relatando como, quando e onde o crime ocorreu, as motivações que levaram os agressores a cometer o crime contra o adolescente e as ações da polícia até então. Ao passo que o caso ganha repercussão, apresentam-se as mobilizações por parte de instituições e de pessoas que se compadeceram com o caso para tentar ajudar o jovem e a família. Novos atores vão surgindo e passam a ter suas falas descritas nas reportagens, como o criador da "vaquinha" on-line, que buscava arrecadar fundos para a remoção da tatuagem, o dono da pensão onde o crime ocorreu e, posteriormente, o dono da bicicleta, que é deficiente físico e relata estar bastante abalado com as proporções que o caso alcançou.

Uma entrevista com o adolescente é exibida em um vídeo, em que este aparece de costas para a câmera, em um cenário que dá a impressão de ser o quintal de uma casa. Apenas a fala do adolescente consta no vídeo e é possível perceber que alguns cortes foram feitos em seu discurso.

Apesar de a matéria trazer o relato do jovem, as falas exibidas se restringem à percepção do jovem em relação ao ocorrido e ao fato deste ser usuário de drogas. Os discursos destacados pelo site no texto das

\footnotetext{
${ }^{6}$ Atividade em que pessoas se juntam contribuindo para atingir determinado objetivo financeiro.
} 
matérias são: "Tive vontade de morrer, comecei a chorar"; "Eu estava bêbado, esbarrei na bicicleta e ela caiu"; e "Eu comecei a puxar o cabelo para a frente para tentar esconder e eles então cortaram meu cabelo". No decorrer do vídeo, outras falas chamam atenção, todavia não tiveram destaque pelo portal de notícias. A exemplo: "Acharam que eu não tinha família, que eu era qualquer um da rua e por isso foram zoar comigo. Acharam que não ia dar nada, mas eu tenho família, eu tenho tudo".

No dia seguinte à exibição da entrevista com o jovem, é noticiado um vídeo com o relato da mãe e do tio da vítima. Neste, os familiares desabafam sobre o caso, manifestam seus anseios por justiça e pedem ajuda para o adolescente, por ele ter transtornos psicológicos e ser usuário de drogas. No texto, as falas da mãe são destacadas, dando ênfase ao julgamento moral ao qual o adolescente está sendo sujeito e à falta de recursos da família para poder ajudá-lo.

Novas informações sobre a prisão dos agressores surgem, e o depoimento de Ariel Alves, advogado do Conselho Nacional de Direitos Humanos (CNDH), que vem acompanhando as investigações sobre o caso, recebe destaque: "Tem que garantir a integridade física deles. Não é porque cometeram um crime grave contra um adolescente que não temos que nos preocupar com a integridade deles também. Que respondam o processo conforme a lei, mas sendo mantidos em local seguro na prisão".

Vale destacar que, ao surgimento da notícia de que um dos agressores, responsável por filmar e divulgar a cena, já havia sido preso por roubo, uma interessante mudança na maneira como o caso é abordado é produzida. Apesar de relatarem a "ironia", a mesma matéria, cuja manchete é: "Homem que filmou adolescente sendo tatuado na testa já cumpriu pena por roubo", aborda em seu texto os antecedentes criminais do adolescente de modo bastante arbitrário e sem contexto adequado durante toda a escrita da matéria.

Em todas as notícias publicadas, o jovem é identificado como "o adolescente de 17 anos que teve a testa tatuada" e, não raro, tal modo de se referir a ele é associado à expressão "tentativa de roubo". Além disso, a partir do momento em que os antecedentes criminais do jovem são expostos e constata-se que este é dependente químico e apresenta "problemas psicológicos", o texto substitui "adolescente" pelo termo "menor".

Curiosamente, uma nova postura em relação aos agressores parece surgir. A imagem destes no momento em que foram presos é substituída por outra cena em que o tatuador aparece cantando e tocando violão em um culto evangélico. Os detalhamentos sobre as ações da Justiça, antes recorrente no texto, dão lugar ao discurso da mãe de um dos agressores alegando que ele agiu por impulso.

A respeito do adolescente, as matérias versam sobre pontos muito específicos: apresenta-se a versão dele, o fato de ser usuário de drogas e apresentar problemas psicológicos, sua internação em uma clínica particular, o início do processo de remoção da tatuagem e, posteriormente, as falas da mãe sobre seu percurso de tratamento na clínica. Quaisquer informações a respeito de seu nome, sua história de vida, escolaridade, tratamentos que fez anteriormente etc. não estiveram presentes em nenhum dos textos analisados. Em contrapartida, a associação dele ao crime de roubo, ao termo "menor", ao uso de álcool e drogas e à presença de transtornos mentais foi frequentemente destacada.

Na cena 2, um jovem de catorze anos, filho de policiais militares e estudante de uma escola particular localizada em um bairro de classe média alta em Goiânia, é autor de diversos disparos dentro da escola, matando dois adolescentes e ferindo outros quatro. A arma utilizada pertencia à mãe do adolescente. Vítima de bullying, o jovem teria planejado o ataque para se vingar dos adolescentes que frequentemente faziam chacotas e difamações contra ele.

$\mathrm{O}$ adolescente foi submetido a avaliação psicológica e, por decisão judicial, foi encaminhado para o cumprimento de medida socioeducativa em privação de liberdade. O caso, ocorrido em outubro de 2017, gerou grande comoção nacional, contando ainda com o pronunciamento de diversas autoridades públicas, como o governador do estado, José Eliton Júnior, e o então presidente Michel Temer, o que não ocorreu na Cena 1.

Dentro do período delimitado para a pesquisa etnográfica, entre outubro de 2017 e janeiro de 2018, foram rastreadas trinta reportagens vinculadas ao caso. Apesar da delimitação do período de três meses, apenas notícias publicadas em outubro e novembro foram encontradas. Além disso, houve atualizações em dias variados em todos os textos publicados. A autoria dos textos é diversificada, contando com a participação de inúmeros jornalistas que trabalham para a TV Anhanguera, afiliada da Rede Globo e responsável pelo noticiamento no estado de Goiás.

O rastreamento descritivo das matérias trouxe à tona a abordagem de temas específicos em relação ao 
caso: em geral, o ponto central das reportagens são as vítimas e seus familiares, além da especulação das motivações do adolescente para efetuar os disparos.

Em todas as matérias analisadas, destacam-se: a narrativa detalhada do ocorrido, o bullying sofrido pelo adolescente autor dos disparos, o relato do delegado que ouviu o jovem e acompanhou o caso, o pânico dos alunos presentes na cena, fotos divulgando o rosto das vítimas do tiroteio, o estado de saúde das demais vítimas que foram hospitalizadas, o depoimento de seus familiares e da coordenadora da escola. A mobilização por parte de autoridades públicas também foi destacada.

É comum a repetição de textos anteriores, especialmente de um infográfico cujo título é "Tiros em colégio", apresentando a sequência de fatos que ilustram como o crime teria ocorrido. A imagem aponta a localização geográfica da escola onde os tiros foram disparados seguida de uma foto na qual policiais militares aparecem na fachada da instituição; o nome dos dois estudantes mortos durante o tiroteio; a arma utilizada; a representação dos quatro feridos, sendo um menino e três meninas; o horário e local exatos do ataque, sinalizando a posição das vítimas no momento dos disparos e da coordenadora, responsável por convencer $\mathrm{o}$ adolescente a cessar $\mathrm{o}$ ataque.

Além do infográfico, o vídeo de uma reportagem que noticia o ocorrido é vinculado em todas as trinta matérias analisadas, informando que o adolescente é filho de policiais militares e estudava no Colégio Goyases. Enfatiza-se o bullying como motivação para o crime e que o adolescente havia "perdido a cabeça" com injúrias que ouvia constantemente de seus colegas.

O jovem teve sua versão da história narrada pelo delegado Luiz Gonzaga, que estava acompanhando as investigações e cedeu entrevista ao portal de notícias. Segundo o delegado, o adolescente teria se inspirado nos massacres de Columbine, que ocorreu em abril de 1999 nos Estados Unidos, matando treze pessoas entre elas doze alunos e um professor-, e o de Realengo, ocorrido em abril de 2011, na Escola Municipal Tasso da Silveira, no Rio de Janeiro, deixando doze mortos.

No mesmo dia em que o caso foi noticiado, o G1 publicou uma matéria especial na coluna
Educação, intitulada "Seis passos básicos contra o bullying. veja do que alunos, pais e escolas precisam para combater a prática"7, relacionando o tema com o ocorrido. As recomendações apontadas por pesquisadores, pedagogos e jornalistas - situados como especialistas - foram: a) reconhecer a existência do bullying, b) conhecer e cumprir a lei de combate ao bullying, c) transformar os valores dos alunos; d) engajar os professores; e) envolver os pais na vida escolar; e f) não subestimar o cyberbullying.

Ainda em relação a essa reportagem, é possível assistir a um vídeo com a fala dos especialistas aprofundando cada umas das recomendações e discutindo formas de prevenção. Na legenda do vídeo, o site destaca uma das falas de Luciene Regina Paulino Tognetta, especialista em educação moral da Universidade Estadual Paulista: "aplausos para os agressores, pais omissos e professores desligados contribuem com bullying".

Chamam atenção as reportagens com trechos de entrevistas com os pais das vítimas apontando que o adolescente deve ser perdoado e não tem culpa do ocorrido. Entretanto, ao analisar somente as chamadas dessas matérias, a impressão passada é a de que culpabilizam os pais do jovem, o que não consta claramente em nenhum dos textos rastreados.

De acordo com o relato do pai, destacado pelo G1:

Não sei até que ponto o colégio conseguiria identificar, não tem culpado, não dá pra saber o que passou na cabeça do menino, até porque atingiu um que ele gostava, não dá pra entender a dor dele. Talvez a gente precise observar os nossos filhos, acompanhar mais. . . Falo como pai do João Pedro, de uma criança que perdeu a vida. Eu espero que toda a sociedade e os pais dele e os outros pais o perdoem. Temos que perdoá-lor.

Somente duas reportagens trazem o relato dos pais do adolescente autor dos disparos. De modo sucinto, noticia-se que, no depoimento prestado à Delegacia de Polícia de Apuração de Atos Infracionais (Depai), o pai do jovem revela não saber que o filho sofria chacota por partes dos colegas com quem estudava e comenta que

\footnotetext{
${ }^{7}$ Recuperado de https://gl.globo.com/educacao/noticia/seis-passos-basicos-contra-o-bullying-veja-do-que-alunos-pais-e-escolasprecisam-para-combater-a-pratica.ghtml

${ }^{8}$ Recuperado de https://gl.globo.com/educacao/noticia/seis-passos-basicos-contra-o-bullying-veja-do-que-alunos-pais-e-escolasprecisam-para-combater-a-pratica.ghtml
} 
não houve negligência em relação ao armazenamento da arma utilizada no crime.

O adolescente em questão não teve o nome nem imagem divulgados. Ele é referenciado nos textos como "o aluno", "o estudante", "o autor dos disparos", "o suspeito de atirar contra colegas" e, principalmente, como "filho de policiais militares". Nas reportagens, é apresentado como alguém que não apresentava comportamentos suspeitos, era bom aluno e carinhoso com a família, apesar de ser uma pessoa quieta e reservada.

Até mesmo após a decisão da Justiça, optando pela internação provisória do jovem, há certo zelo: o promotor de Justiça que deferiu a privação de liberdade do jovem tem uma de suas falas destacadas pelo site: "Essa medida deve ser retocada de certos cuidados em virtude de ser filho de policiais militares para não colocar no meio de elementos perigosos que possam causar algumas represálias".

O destaque para a fala da advogada da família também evidencia tal observação: "Ele disse que está arrependido. Ele está abalado, como o pai, a mãe, todo mundo. A mãe está internada, o pai visivelmente não está bem. Ninguém imaginava que isso pudesse acontecer". Na mesma notícia, é exibido vídeo de uma reportagem do Jornal Nacional, ao qual é atrelada certa comoção em relação à medida de internação: uma repórter fala que a família teme pela vida do menino e tenta adiar a saída da delegacia. Em seguida, aparece a advogada informando que "o centro de internações daqui não é seguro por conta da repercussão do caso, por conta dos pais serem militares, e o pai já coordenou a segurança do batalhão do sistema prisional, o que traz mais insegurança para a vida do menino".

A última matéria publicada se refere à decisão da Justiça sobre o caso. Noticia-se que o adolescente ficará internado em regime de semiliberdade por até três anos. O deferimento é tratado como medida protetiva ao jovem, considerando a repercussão que o caso alcançou. Especula-se se o crime poderia ou não ser evitado, uma vez que o parecer psicológico ao qual o adolescente foi submetido, de acordo com a matéria, indicou traços que demandavam atenção por parte da família e da escola. Por fim, ressalta-se que, após o cumprimento da medida, o adolescente não terá antecedentes criminais e poderá retornar ao convívio em sociedade.

Tratando das particularidades da construção e subsequente noticiamento de cada umas das cenas exploradas, as discussões aqui propostas são fomentadas por elementos distintos. Em "Sou ladrão e vacilão”, muito embora o número de publicações seja menor se comparado ao da segunda cena ("Atirador na escola”), percebe-se que o interesse midiático em seu noticiamento perdurou por mais tempo. Os motivos disso não ficam explícitos, mas se valem de algumas considerações com base na exposição acerca da concepção de "menor infrator" explorada anteriormente.

Os dados possibilitaram considerar que a mídia dispõe dos mecanismos necessários para trazer reflexões mais profundas, no entanto seu papel social e transformador sucumbe aos interesses particulares e ideológicos dos veículos midiáticos. Percebe-se claramente tal movimento em relação à segunda cena, em que, logo após a divulgação do bullying como motivação para o ato infracional do adolescente, surge uma reportagem especial sobre a temática, contando com a participação de especialistas orientando escola, familiares e a comunidade. O link para a reportagem esteve atrelado a 27 das trinta matérias analisadas, demonstrando a importância direcionada pelo G1 ao tema.

Na contramão, vemos que, na primeira cena, a justificativa noticiada para a tatuagem no adolescente foi a tentativa de roubo, especulando-se uma associação entre furto e uso de drogas, o que não foi reconhecido pela opinião pública como justificativa para o acontecimento, e a possibilidade de doença mental explicada pela mãe sequer foi considerada. Embora as motivações dos ocorridos em uma cena e outra tenham diferenças entre si, não caberia o levantamento de uma discussão acerca do uso de drogas e tantos outros diálogos pertinentes, tal como ocorreu em relação ao bullying? Não foram convocados especialistas para discutir o caso. A questão das drogas permanece associada à criminalidade, e as contribuições pertinentes ao campo da Saúde Pública não são consideradas.

Tratando das similaridades nos dois casos, a família surge enquanto objeto de interesse na construção das narrativas. No primeiro, vemos um embate entre a angústia de duas mães ser fomentado. De um lado, a mãe do adolescente que pede por justiça e por ajuda para o filho e, do outro, a mãe do tatuador que clama para que seu filho não seja visto como um monstro. Tal embate não só coloca em dicotomia vítima versus agressor como também faz emergir a ideia de justiçamento como forma de lidar com o problema da criminalidade.

Na segunda cena, o sofrimento dos familiares - tanto do jovem quanto das vítimas - é trazido 
frequentemente. Contudo o que se percebe é que a todo instante são apresentados elementos na construção dos textos que inocentam e/ou justificam as motivações para o crime efetuado pelo jovem. Nesse sentido, Silva e Moura (2008), refletem que a mídia produz "verdades", pontuando quem deve ser vigiado e quais discursos devem ou não ser atribuídos em cada caso.

Outro ponto destacado é a forma como os dois protagonistas são apresentados nas reportagens. Ao longo do acompanhamento, vemos uma superexposição do jovem na primeira cena, tendo sua imagem com a tatuagem na testa sendo exibida de modo indiscriminado e pouco comprometido com a repercussão que tal cena poderia gerar. Vale ressaltar que, assim tal como a exposição do vídeo da tatuagem, a divulgação de seus antecedentes criminais viola a Lei no 8.069, em seu artigo 232 (Brasil, 1990), que prevê a criminalização da submissão de criança ou adolescente a vexame ou constrangimento.

Embora o adolescente da segunda cena também seja frequentemente associado ao crime que cometeu, há um movimento de proteção em relação a ele, divulgando apenas imagens das vítimas e destacando discursos que tornam o ocorrido uma surpresa a todos, e não algo que pudesse ser esperado por parte de um jovem de classe média e filho de policiais militares, fato este que inclusive é utilizado pela defesa do adolescente.

Ao analisarmos os discursos destacados pelos dados etnográficos, vemos duas formas distintas na maneira de tratar os casos, produzindo diferentes subjetividades em relação aos seus protagonistas. É na constante ênfase dada ao uso de drogas, aos antecedentes criminais e na associação do termo "menor" ao jovem da cena 1 e na exploração de elementos morais (família e religião) nos discursos sobre seus agressores que se verifica a produção de um adolescente portador de todos os critérios que justificariam, dentro da lógica punitiva, o crime de tortura efetuado contra o adolescente. Em contrapartida, em relação ao jovem de classe média, acompanha-se a gradativa inserção de elementos capazes de produzir em nós uma certa comoção, uma vez que sua história de vida é abordada na tentativa de entender o ocorrido, levando-nos a tratar o caso como tragédia e refletir criticamente a respeito dos diversos fatores que o propiciaram.

Além disso, há um elemento em comum que, apesar de explícito nas narrativas, ocupa posições diferentes nas duas cenas: ambos têm problemas psicológicos.
Todavia, ao passo que no primeiro caso isso é completamente ignorado, o crime ocorrido na segunda cena só poderia ter ocorrido por essa razão.

Há de se destacar ainda que o noticiamento da primeira cena perdurou mesmo após a internação do adolescente em uma clínica de tratamento para dependência química. $\mathrm{O}$ caso retorna às mídias quando o jovem é detido, meses depois, por furtar desodorantes, enfatizando a reincidência e retomando a discussão sobre o crime de tortura contra ele ter sido merecido. $\mathrm{O}$ mesmo não acontece em relação à segunda cena, uma vez que, após a decisão de que o jovem autor dos disparos cumpriria a medida de privação de liberdade, cessaram-se as reportagens e comentários a respeito do caso.

Na prática, quando um jovem pobre e periférico está envolvido em qualquer tipo de ato infracional, os indicadores políticos, econômicos e sociais que auxiliam na compreensão desse fenômeno pouco são discutidos. Contudo, se um jovem de classe média comete um delito, parece surpreender a todos, sendo necessária, a partir disso, a apresentação de elementos que justifiquem ou tornem plausível o ato infracional. Conforme os apontamentos realizados anteriormente, a associação da pobreza à criminalidade é tida como inerente e previamente esperada.

Por fim, há de se destacar que a necessidade de garantir a integridade física dos agressores do jovem na primeira cena, bem como a preocupação para que o adolescente cumpra a medida em local seguro, no caso do "atirador na escola em Goiânia", são pontos consonantes com os princípios dos direitos fundamentais. Entretanto não parece haver interesse por parte do portal de notícias em explicitar esses aspectos e promover reflexões mais profundas sobre a universalização dos direitos humanos.

\section{Considerações finais}

A proposta deste trabalho se encarrega de pensar a produção do "menor infrator" pela mídia brasileira e quais os efeitos dessas produções na construção de determinada realidade. Interessou-nos discutir a capacidade que os dispositivos midiáticos têm de operar em nós formas de compreender o mundo, modelando nossas subjetividades e direcionando o modo como enxergamos fenômenos como, por exemplo, o da criminalidade.

Apesar do Estatuto da Criança e do Adolescente ser um importante marco na luta por direitos no Brasil, contrapondo-se a um passado de controle e 
exclusão social, observamos que, desde sua promulgação em 1990, este é alvo constante de críticas, sendo significativa e cíclica a presença de projetos de lei e de emendas constitucionais que buscam alterar os dispositivos da Constituição Federal e do Estatuto. As justificativas apresentadas são pautadas nos clamores por mais castigo e punição como estratégias de enfrentamento ao fenômeno da violência, reaparecendo de tempos em tempos, especialmente nos momentos em que crimes envolvendo jovens ganham repercussão na mídia.

Assim, a associação entre juventude e violência vem se constituindo ao longo dos anos, proveniente da cultura do medo que se instala na sociedade. Promovida e incentivada principalmente pelos dispositivos midiáticos, vem se fortalecendo, dia após dia, por meio de "amostras de violência, geralmente associadas a pobres, negros ou bairros suburbanos, em uma nítida inferiorização e periculorização das classes desfavorecidas" (Oliveira, Rezende, \& Bicalho, 2017, p. 120).

As discussões aqui propostas fazem refletir que a noção errônea de impunidade, na qual o adolescente em conflito com a lei é frequentemente relacionado, representa um obstáculo para a plena efetivação do texto integral do ECA, na medida em que promovem o clamor social por penas mais rigorosas. As críticas arbitrárias promovidas por autoridades públicas e por narrativas midiáticas de cunho sensacionalista com as quais deparamos no debate sobre a redução da maioridade constantemente ignoram as obrigações do Estado no que tange às questões de segurança pública e tampouco cumprem seu papel de esclarecer a sociedade acerca da legislação e dos inúmeros fatores - políticos, econômicos e sociais que atravessam a problemática da infração juvenil.

O fenômeno contemporâneo do ato infracional juvenil no Brasil se deve, sobretudo, à desigualdade social, ao não exercício da cidadania e às dificuldades das políticas públicas existentes alcançarem parcela expressiva de adolescentes, tornando cada vez mais urgente e necessária a promoção dos direitos fundamentais e sociais preconizados na legislação vigente. Observa-se que as estratégias atuais permanecem produzindo uma cisão entre "crianças" e "menores", a partir da situação de abandono ou de infração, perpetuando na prática direitos distintos para essa população.

Com esta pesquisa, não propomos demonizar as mídias ou responsabilizá-las pelas mazelas sociais. Interessa-nos dar visibilidade ao modo como verdades são construídas e veiculadas por esses dispositivos e seus efeitos na produção de sujeitos anormais, perigosos e possuidores de uma índole ruim, que se configura enquanto importante estratégia de segregação e exclusão social.

Apostamos no compromisso ético-político da Psicologia na problematização de questões sociais e convocamos os profissionais da área a ocuparem espaços midiáticos a fim de desconstruir posicionamentos instituídos e desvelar os processos de produção desses sujeitos e ao que serve diferenciar crianças e adolescentes que devem ser protegidos de menores que oferecem riscos à sociedade.

\section{Referências}

Arendt, R., \& Tsallis, A. (2006). O(s) cotidiano(s) do(s) Rio(s) de Janeiro. In M. J. Spink, \& P. Spink (Orgs.), Práticas cotidianas e naturalização da desigualdade: Uma semana de notícias nos jornais (pp. 64-73). São Paulo, SP: Cortez.

Bocco, F. (2006). Cartografias da Infração Juvenil (Dissertação de mestrado). Universidade Federal Fluminense, Niterói, RJ.

Cairo, C. B., \& Milanez, N. (2011). "Menor Infrator", sociedade de controle e construção do sujeito: Embates na mídia impressa e televisiva. Anais do SILEL: Simpósio Internacional de Letras e Linguística, 2(2), 1-20.

Coimbra, C. (2001). Operação Rio: O Mito das Classes Perigosas: Um estudo sobre a violência urbana, a mídia impressa e os discursos de segurança pública. Rio de Janeiro, RJ: Intertexto.

Coimbra, C. (2004). Mídia e produção de modos de existência. Revista Psicologia: Teoria e Pesquisa, 17(1), 1-4. http://www.scielo.br/scielo.php?pid=S0102-37722001000100002\&script=sci_abstract\&tlng=pt

Coimbra, C., \& Nascimento, M. L. (2005). Ser jovem, ser pobre é ser perigoso? https://app.uff.br/slab/uploads/ texto23.pdf

Flacso Brasil. (2017). Mapa da violência: adolescentes de 16 e 17 anos no Brasil. https:/ /bit.ly/356OEmO 
Guattari, F., \& Rolnik, S. (1986). Micropolítica: Cartografias do desejo (4a ed.). Petrópolis, RJ:Vozes.

Brasil. (2017). Índice de vulnerabilidade juvenil à violência: Desigualdade racial e municípios com mais de 100 mil habitantes. http://www.forumseguranca.org.br/publicacoes/indice-de-vulnerabilidade-juvenil-a-violencia-2017desigualdade-racial-e-municipios-com-mais-de-100-mil-habitantes/

Instituto De Pesquisa Econômica Aplicada. (2013). Nota técnica: O Adolescente em Conflito com a Lei e o Debate sobre a Redução Da Maioridade Penal: Esclarecimentos Necessários. https://www.ipea.gov.br/portal/index. php?option=com_content\&view=article\&id $=25620$

Latour, B. (2012). Reagregando o Social: uma introdução à Teoria Ator-Rede. Bauru, SP: EDUSC; Salvador, BA: EDUFBA.

Lei no 8.069 de 13 de julho de 1990. (1999). Estatuto da criança e do adolescente. Brasília, DF: Presidência da República. http://www.planalto.gov.br/ccivil_03/leis/18069.htm

Londoño, FT. (1991). A origem do conceito menor: In M. D. Priore, História da criança no Brasil. São Paulo, SP: Contexto.

Oliveira, C. S. (2001). Sobrevivendo no inferno: A violência juvenil na contemporaneidade. Porto Alegre, RS: Sulina.

Oliveira, M., Rezende, \& R., Bicalho, P. (2018). Direitos humanos, segurança pública e a produção do medo na contemporaneidade. Cadernos Brasileiros de Saúde Mental, 10(25), 118-140.

Rifiotis, T. (2016). Etnografia no ciberespaço como "repovoamento" e explicação. In J. Segata, \& T. Rifiotis, Políticas etnográficas no campo da cibercultura. Joinville, SC: Letradágua.

Segata, J., \& Rifiotis, T. (2016). Políticas etnográficas no campo da cibercultura. Joinville, SC: Letradágua.

Silva, C. A. V. (2017). A categoria social do "menor" [Apostila do curso de especialização em políticas públicas e socieducação]. Brasília, DF: ENS.

Silva, M. P., \& Moura, C. B. (2008). Mídia e a figura do anormal na mira do sinóptico: A constituição discursiva de subjetividades femininas. Revista Estudos Feministas, 16(3), 841-855.

Teixeira, J. D. (2015). Dispositivos de controle social da juventude: O encarceramento na casa sobre a lógica da gestão dos riscos e/ou proteger para controlar. https://www.marilia.unesp.br/Home/Eventos/2015/ iseminariointernacionalpos-graduacaoemcienciassociais/3.-joana-d-arc-teixeira.pdf

Uzzell, D., \& Barnett, J. (2010). Pesquisa etnográfica e pesquisa-ação. In G. M., Breakwell, C. F. Schaw, S. Hammond, \& J. Smith. (2010). Métodos de pesquisa em psicologia (3a ed.). Porto Alegre, RS: Artmed.

Francyne dos Santos Andrade

Graduada em Psicologia pela Universidade Católica de Petrópolis (UCP). Membro do grupo de pesquisa Psicologia e Mídia da UCP e colaboradora do Conselho Regional de Psicologia do Rio de Janeiro, Subsede Região Serrana, Petrópolis - RJ. Brasil.

E-mail: francyne.sandrade@gmail.com

(1) https://orcid.org/0000-0003-4820-3846

Cristiane Moreira da Silva

Doutora em Psicologia pela Universidade Federal Fluminense. Professora dos cursos de Graduação e Mestrado em Psicologia da Universidade Católica de Petrópolis (UCP). Coordenadora da Pós-Graduação Lato Sensu em Avaliação Psicológica da UCP, Petrópolis - RJ. Brasil.

E-mail: cristiane.moreira@ucp.br

(1) https://orcid.org/0000-0001-8496-0233

\section{Rosilene Ribeiro}

Mestre em Educação pela Universidade Católica de Petrópolis (UCP). Coordenadora e professora do Curso de Graduação em Psicologia da UCP. Petrópolis - RJ. Brasil.

E-mail: rosilene.ribeiro@ucp.br

(1) https://orcid.org/0000-0003-1036-0600 
Endereço para envio de correspondência:

Universidade Católica de Petrópolis. Campus Dom Veloso. Rua Benjamin Constant, CCXIII, Centro.

CEP: 25610-130. Petrópolis - RJ. Brasil.

Recebido 09/12/2018

Aceito 06/04/2020

Received 09/12/2018

Approved 06/04/2020

Recibido 09/12/2018

Aceptado 06/04/2020

Como citar: Andrade, F. S., Silva, C. M., \& Ribeiro, R. (2020). O “Menor Infrator" na Mídia: Etnografia da Criminalização da Pobreza no G1. Psicologia: Ciência e Profissão, 40, 1-14.

https://doi.org/10.1590/1982-3703003217509

How to cite: Andrade, F. S., Silva, C. M., \& Ribeiro, R. (2020). The “Juvenile Offender" on Media: Ethnography of the Poverty Criminalization in the G1. Psicologia: Ciência e Profissão, 40, 1-14.

https://doi.org/10.1590/1982-3703003217509

Cómo citar: Andrade, F. S., Silva, C. M., \& Ribeiro, R. (2020). El Menor Infractor en Los Medios: Etnografía de la criminalización de la pobreza en el G1. Psicologia: Ciência e Profissão, 40, 1-14.

https://doi.org/10.1590/1982-3703003217509 